\title{
Diagnosis of a growing radiation-induced skull lesion in a patient: an unusual scar
}

\author{
Andrea P. Perera, BSc, ${ }^{1,2}$ Gautam U. Mehta, MD, ${ }^{2}$ Drew Pratt, MD, ${ }^{3}$ Martha M. Quezado, MD, ${ }^{3}$ \\ Mark R. Gilbert, MD, ${ }^{4}$ and John D. Heiss, MD $^{2}$
}

'Barts and the London SMD, Queen Mary University of London, United Kingdom; ${ }^{2}$ Surgical Neurology Branch, National Institute of Neurological Disorders and Stroke; ${ }^{3}$ Laboratory of Pathology; and ${ }^{4}$ Center for Cancer Research, National Cancer Institute, National Institutes of Health, Bethesda, Maryland

\begin{abstract}
New lesions arising from within an area of previous irradiation often present a diagnostic dilemma, with new malignancy or metastasis of particular concern. The authors report a case of reactive fibroblast proliferation emerging from a previous radiation field and presenting as a growing lesion of the frontal and parietal skull. Following complete gross resection of the skull lesion and histopathological analysis, it was discovered that this lesion consisted of dense fibroblast proliferation with areas of osteonecrosis. This unusual reactive phenomenon offers a novel differential diagnosis for a new contrast-enhancing lesion in a region of previous radiation.
\end{abstract}

http://thejns.org/doi/abs/10.3171/2015.7.JNS15989

KEY WORDS fibroblast; lesion; skull; radiotherapy; oncology

$\mathrm{N}$ EW contrast-enhancing lesions of the skull within a site of previous irradiation are a diagnostic challenge, with the differential diagnoses ranging from radiation-induced malignancy to osteoradionecrosis of the bone. ${ }^{10,12}$ Nonmalignant conditions associated with highdose radiation include radiation-induced fibrosis as well as infrequently reported cases of cranial fasciitis, a rare mesenchymal lesion predominantly observed in childhood. ${ }^{13}$ The presentation of such lesions provides a diagnostic dilemma, with little differentiation between benign and malignant phenomena both clinically and on traditional imaging.

We describe a case of radiation-induced scarring and fibroblast proliferation presenting as a growing, welldemarcated, contrast-enhancing lesion of the frontal and parietal skull 3 years after high-dose radiation therapy for an initially misdiagnosed frontoparietal WHO Grade II ependymoma.

\section{Case Report}

History

A 60-year-old Tunisian woman presented to a local medical center in August 2012 with intermittent left-sided facial droop. Magnetic resonance imaging of the brain demonstrated an enhancing lesion in the right frontopa- rietal region with an associated cystic component. She underwent gross-total resection in November 2012. Her postoperative course was unremarkable, and the pathological diagnosis at the time was thought to be glioblastoma. Postoperative MRI in December 2012 showed contrast enhancement in the area of the resection cavity thought to represent residual disease. She received cranial radiotherapy for a total dose of 60 Gy over 30 fractions, then 6 cycles of maintenance temozolomide. Follow-up imaging performed a year after surgery in November 2013 showed that the area of enhancement had reduced in size, with full resolution of the cystic component.

She first presented to the National Institutes of Health in January 2014 for evaluation, and her original pathology was reevaluated, leading to a revised diagnosis of WHO Grade II ependymoma. Serial imaging performed over the next year demonstrated progressive improvement of the frontoparietal brain lesion. However, a new enhancing extraaxial lesion was noted in the right frontoparietal skull, first noted in September 2014 and found to be growing on serial imaging 6 months later (Fig. 1). This lesion was within the previous radiation field but located just outside the previous craniotomy along the coronal suture. Evidence of bone erosion into the frontoparietal skull was present on bone window CT imaging. 


\section{Operation}

The patient underwent surgery using a navigational system to center the skin incision and craniectomy. The superior limb of the previous scalp incision was opened and extended anteriorly to allow retraction of the scalp superior to the previous craniotomy. The periosteum was preserved over the bone lesion, which was located just superior to the previous craniotomy and bisected by the coronal suture. The bone was burred circumferentially around the involved bone (Fig. 1). The lesion was noted to be firmly adherent to dura mater; hence, the underlying dural attachment was excised with the lesion en bloc. The dura was closed with a patch of allogeneic pericardium. Titanium mesh was placed over the skull defect, and the scalp was closed in 2 layers.

\section{Histopathological Findings}

The skull specimen measured $2.5 \times 0.8 \times 1.8 \mathrm{~cm}$. A 2.1 $\times 0.5 \times 1.7-\mathrm{cm}$ well-demarcated rubbery lesion was present, adjacent to bone and dura (Fig. 2). Histopathological examination displayed fibroblastic proliferation with minimal to no atypia; areas of osteonecrosis and bone marrow fat necrosis were also present. Immunohistochemical analysis showed that the lesional cells were negative for epithelial membrane antigen (EMA), CD-34, and S100. The overall features were consistent with a reactive process. A diagnosis of reactive radiation-induced scarring was made.

\section{Discussion}

This case highlights the challenges in determining the etiology of a suspected radiation-induced skull lesion. In this patient the differential diagnoses included metastasis of primary tumor, radiation-induced tumor (particularly meningioma, given the dural attachment noted at surgery), an infectious agent, or a radiation-induced reactive process (Table 1). Given the relatively rapid growth and bone erosion, there was the possibility of malignancy leading to the need for tissue diagnosis. Given the extraaxial location, the benefits of resection compared with biopsy were felt to outweigh the risks. As described above, histopathological analysis demonstrated that the lesion was reactive in origin.

While radiation-induced fibrosis and scarring are wellreported entities in soft tissue, ${ }^{8}$ we describe an unusual presentation of fibroblast proliferation and infiltration into the skull with osteonecrosis and fat necrosis of the bone marrow presenting as a discrete, growing skull lesion. Radiation is known to cause excessive fibrous tissue formation and the loss of normal cell physiology. ${ }^{1}$ Radiationinduced fibrosis usually affects the soft tissues and is well characterized in the lungs, skin, and subcutaneous tissues. Lesions usually present as diffuse areas of fibrosis associated with significant degrees of inflammation. ${ }^{7}$ The lesion presented here is thought to represent a unique manifestation of radiation-induced scarring. Rather than a diffuse fibrotic reaction of soft tissue, it displays a discrete proliferation of well-differentiated fibroblasts in bone. This is, to our knowledge, the first report of radiation-induced fibroblast proliferation presenting in the skull.

Microscopic evaluation of the entire lesion did not demonstrate features of a neoplastic process such as meningioma or involvement by the patient's known ependymoma. The lesion was present within the radiation field along the coronal suture, making the lesion likely to result from the high dose of radiation delivered to this region. The possibility that this scar-like lesion arose from the previous craniotomy scar was considered but is less likely as a small margin of normal bone between the lesion
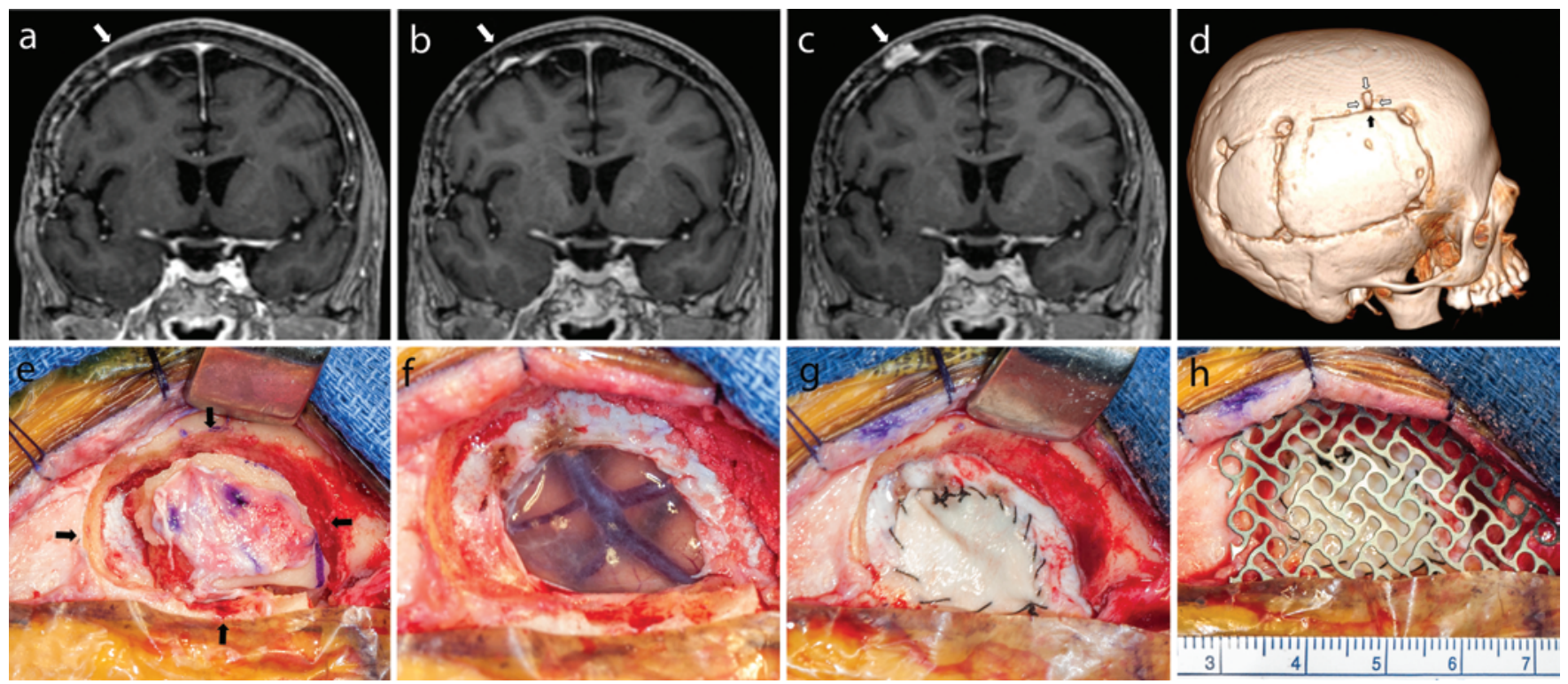

FIG. 1. Radiological lesion evolution and operative procedure. Coronal MRI slices display evolution of the lesion (white arrows) starting at 17 months (a), 21 months (b), and 28 months (c) after radiotherapy. Computed tomography reconstruction (d) of the skull obtained 28 months after radiotherapy (inferior black arrow points to skull defect; all arrows point to bone later removed by craniectomy). Craniectomy around bone lesion (e) before en bloc lesion removal. Intact arachnoid and cortex are visible after lesion removal (f), as are duraplasty (g) and titanium cranioplasty (h). 

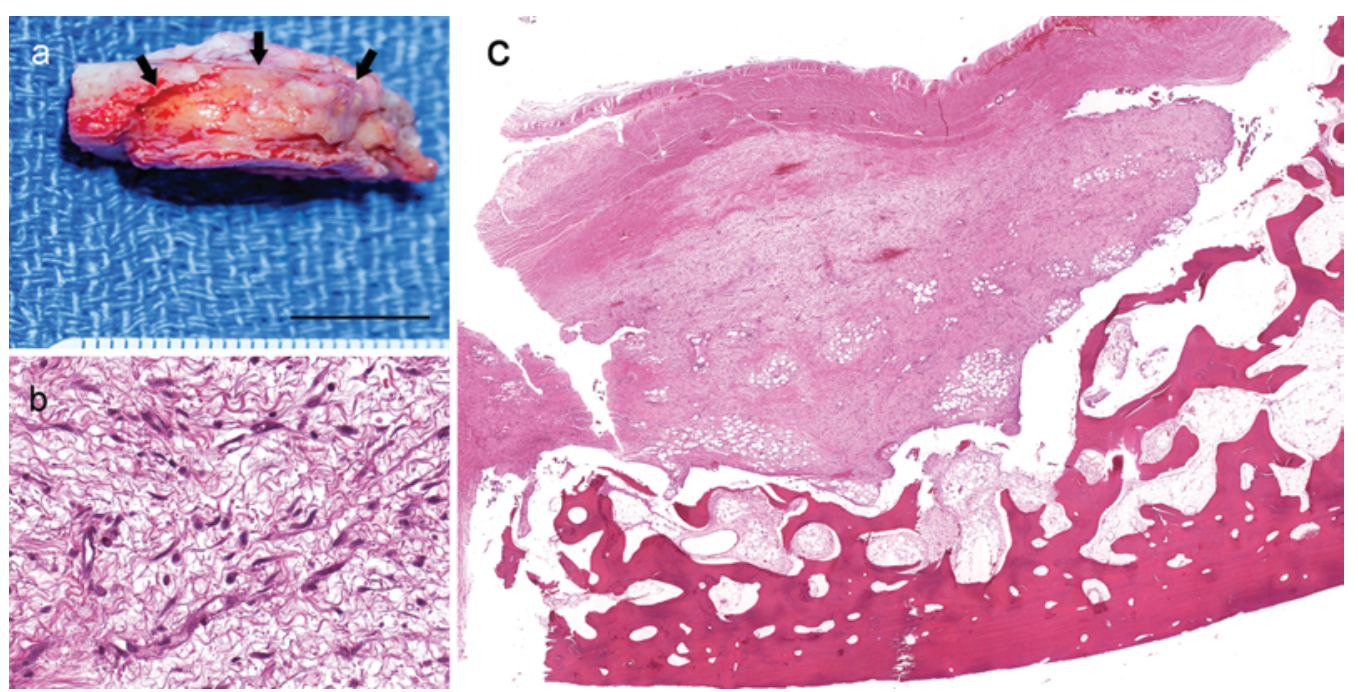

FIG. 2. Gross and histopathological findings. Gross evaluation (a) demonstrates a well-delimited white, rubbery lesion attached to dura and bone (arrows). Tissue sections ( $b$ and c) show a proliferation of bland spindle cells with minimal to no atypia. $\mathrm{H} \& \mathrm{E}$, original magnification $\times 200$ (b) and $\times 20$ (c).

and the craniotomy line was observed during the operation. Serial MRI shows the lesion to be absent 17 months following radiation but present in the 21- and 28-month scans. This finding indicates that radiation-induced scarring can lie dormant for some time and sporadically become active again.

The differential diagnosis includes cranial fasciitis, a benign lesion seen to arise in the cranial region, which shares its pathological features with nodular fasciitis, with fibroblastic proliferation, mitotic bodies, and sarcomalike features. ${ }^{11}$ It is a rare condition that largely presents in children following a variety of stimuli and at a median age at onset of 1 year (range 2 weeks-11 years), with only the sporadic case reported in adults. ${ }^{11} \mathrm{~A}$ case series of 7 patients showed that nodular fasciitis of the head and neck presented most commonly with discrete, softtissue, contrast-enhancing lesions measuring $2.2 \mathrm{~cm}$ in diameter on average, showing distinct similarities to the case presented. ${ }^{5}$ Other reported cases with dural involvement share characteristics with our case. ${ }^{9}$ Cranial fasciitis is thought to occur after trauma, and cases have been reported following radiation therapy in children but not in adults. ${ }^{13}$ Additionally, none of the previous reports display bone invasion as seen in the case presented here., Finally, the presence of bone marrow fat necrosis and osteonecrosis are not typical features associated with cranial fasciitis. In the case presented here, radiation resulted in necrosis of the overlying bone, proliferation of fibroblasts, and invasion of the fibroblasts into the radiation-softened bone. The rapid progressive growth of this lesion necessitated operative management; therefore, serial MRI was sufficient to make a management decision. However, in a slow-growing or static lesion presenting in a similar fashion, a preemptive diagnosis may be of assistance. Recent advances in imaging and the wide variety of modalities available offer opportunities in which to differentiate between benign and malignant lesions. Reports have shown that T2-weighted MRI, MR spectroscopy, and PET have shown success in differentiating between classic radiation fibrosis and tumor recurrence in soft tissues. ${ }^{2,3,6}$ It is unknown if these techniques could be extended to bony lesions to differentiate radiation-induced scarring from tumor recurrence or radiation-induced tumor. ${ }^{4}$ While PET or spectroscopy may be able to differentiate between a

\section{TABLE 1. Other postradiation skull lesions}

\begin{tabular}{|c|c|c|}
\hline Disease & Factors Favoring Diagnosis & Factors Against Diagnosis \\
\hline $\begin{array}{l}\text { Radiation-induced } \\
\text { meningioma }\end{array}$ & $\begin{array}{l}\text { Occurs in areas of previous irradiation; presents as an } \\
\text { extraaxial lesion; dural attachment noted intraop }\end{array}$ & Typically does not invade bone \\
\hline $\begin{array}{l}\text { Radiation-induced } \\
\text { osteosarcoma }\end{array}$ & $\begin{array}{l}\text { Most common primary bone malignancy postradio- } \\
\text { therapy; radiation-induced osteosarcoma of the skull } \\
\text { reported in patients receiving }>50 \text { Gy of radiation }{ }^{13}\end{array}$ & Produces an irregular osteolytic lesion \\
\hline Infection & Rapid growth & $\begin{array}{l}\text { Patients would be expected to have clinical signs \& symptoms of } \\
\text { infection }\end{array}$ \\
\hline Cranial fasciitis & $\begin{array}{l}\text { Known association w/ sites of previous radiation; }{ }^{3} \text { pre- } \\
\text { sents as a well-demarcated soft-tissue lesion }{ }^{6}\end{array}$ & $\begin{array}{l}\text { Predominates in children; does not show features of osteonecrosis \& } \\
\text { bone marrow fat necrosis; does not typically invade bone }\end{array}$ \\
\hline $\begin{array}{l}\text { Metastasis of } \\
\text { primary tumor }\end{array}$ & Rapid growth; known primary tumor & $\begin{array}{l}\text { Radiation not known to cause bony invasion; late metastasis of WHO } \\
\text { Grade II ependymoma is unlikely w/o associated local recurrence }\end{array}$ \\
\hline
\end{tabular}


malignant, metabolically active lesion and a benign one, at present the only way to definitively diagnose this lesion is by histopathological examination. Furthermore, as the natural history of such a lesion is currently unknown, for now excision remains the treatment of choice.

\section{Conclusions}

The case presented here illustrates that imaging is often not definitive in diagnosing contrast-enhancing lesions of the skull presenting in an area exposed to radiation. This case demonstrates that fibroblastic, reactive proliferation following radiotherapy can be an indolent, sporadic process occurring more than 2 years following the completion of radiotherapy. Lesions in the skull following irradiation have a wide range of differential diagnoses, which are not always malignancies. Radiation-induced "scarring" and fibroblastic lesions should be considered as possibilities in patients presenting with contrast-enhancing lesions of the skull within a previous radiation field.

\section{Acknowledgments}

This work was supported by the Intramural Research Program at the National Institute of Neurological Disorders and Stroke (NINDS) at the National Institutes of Health (NIH).

The intraoperative images were kindly provided by the medical photography department at the NIH, Bethesda.

\section{References}

1. Anscher MS: The irreversibility of radiation-induced fibrosis: fact or folklore? J Clin Oncol 23:8551-8552, 2005

2. Charles HC, Baker ME, Hathorn JW, Sostman D: Differentiation of radiation fibrosis from recurrent neoplasia: a role for 31P MR spectroscopy? AJR Am J Roentgenol 154:67-68, 1990

3. Gong QY, Zheng GL, Zhu HY: MRI differentiation of recurrent nasopharyngeal carcinoma from postradiation fibrosis. Comput Med Imaging Graph 15:423-429, 1991

4. Ito T, Ozaki Y, Sato K, Oikawa M, Tanino M, Nakamura H, et al: Radiation-induced osteosarcomas after treatment for frontal gliomas: a report of two cases. Brain Tumor Pathol 27:103-109, 2010

5. Kim ST, Kim HJ, Park SW, Baek CH, Byun HS, Kim YM:
Nodular fasciitis in the head and neck: CT and MR imaging findings. AJNR Am J Neuroradiol 26:2617-2623, 2005 (Erratum in AJNR Am J Neuroradiol 27:249, 2006)

6. Nakajima N, Sugawara Y, Kataoka M, Hamamoto Y, Ochi T, Sakai S, et al: Differentiation of tumor recurrence from radiation-induced pulmonary fibrosis after stereotactic ablative radiotherapy for lung cancer: characterization of $18 \mathrm{~F}-\mathrm{FDG}$ PET/CT findings. Ann Nucl Med 27:261-270, 2013

7. Okunieff P, Augustine E, Hicks JE, Cornelison TL, Altemus RM, Naydich BG, et al: Pentoxifylline in the treatment of radiation-induced fibrosis. J Clin Oncol 22:2207-2213, 2004

8. Rodemann HP, Bamberg M: Cellular basis of radiationinduced fibrosis. Radiother Oncol 35:83-90, 1995

9. SantaCruz K, Brace J, Hall W: A case of cranial fasciitis originating within the diploic space of an adult: case report. Neurosurgery 61:E1338, 2007

10. Støre G, Smith HJ, Larheim TA: Dynamic MR imaging of mandibular osteoradionecrosis. Acta Radiol 41:31-37, 2000

11. Summers LE, Florez L, Berberian ZJ, Bhattacharjee M, Walsh JW: Postoperative cranial fasciitis. Report of two cases and review of the literature. J Neurosurg 106:1080-1085, 2007

12. Thiagarajan A, Iyer NG: Radiation-induced sarcomas of the head and neck. World J Clin Oncol 5:973-981, 2014

13. Wu B, Zhu H, Liu W, Chen L: Occipital diploic cranial fasciitis after radiotherapy for a cerebellar medulloblastoma. J Neurosurg Pediatr 12:637-641, 2013

\section{Disclosures}

The authors report no conflict of interest concerning the materials or methods used in this study or the findings specified in this paper.

\section{Author Contributions}

Conception and design: Heiss, Mehta, Quezado, Gilbert. Drafting the article: Heiss, Perera, Pratt, Quezado, Gilbert. Critically revising the article: all authors. Reviewed submitted version of manuscript: Heiss, Perera. Administrative/technical/material support: Mehta, Pratt. Study supervision: Mehta, Quezado.

\section{Correspondence}

John Heiss, National Institutes of Health, Surgical Neurology Branch, National Institute of Neurological Disorders and Stroke, 10 Center Dr., Rm. 3D20, MSC-1414, Bethesda, MD 20892. email: heissj@ninds.nih.gov. 